\title{
Analysis of Factors Affecting Poverty Depth Index in Papua Province Using Panel Data Regression
}

\author{
Rufina Indriani*, Erma Oktania Permatasari
}

\author{
Department of Statistics, Sepuluh Nopember Institute of Technology \\ *Corresponding author. Email: rufinaindriani2088@gmail.com
}

\begin{abstract}
One of the main problems in Papua Province is poverty, because the Poverty Depth Index (P1) in Papua Province is greater than other province, which was 7.17 in 2019. This value is bigger than the Poverty Depth Index in Indonesia which was only 1.55. This study will analyse the factors that affect the Poverty Depth Index in Papua Province in District/City in 2012 until 2019 using the panel data regression method. Panel data regression is used because this method can combine cross section data with time series data. The results of the selection of best model show that the best model is Fixed Effect Model (FEM) and test assumptions of residual covariance variance structure show that the model has heteroscedasticity structure. Therefore, the best model is Fixed Effect Model (FEM) with cross-section weighted. The model has an R-square value of $82.5 \%$ with significant variables are Human Development Index and average expenditure per capita in one month.
\end{abstract}

Keywords: Fixed Effect Model (FEM), Poverty depth index, Panel data regression.

\section{INTRODUCTION}

Poverty is one of the global issues faced by many countries, so it is included in the first goal of the Sustainable Development Goals (SDGs). The goal is to eliminate poverty and end poverty everywhere and in all its forms. Poverty is also a priority issue for the Indonesia government. The government has set a target for reducing the poverty rate by $7 \%$ to $8 \%$ [1]. Poverty is the inability of the community to meet food and non-food needs in terms of economy or expenditure and can be measured based on Food Poverty Line and Non-Food Poverty Line.

One of the measure of poverty is Poverty Gap Index (P1) which is a measure of the regional poverty gap. The Poverty Depth Index is measured from the average expenditure gap of each poor population against the poverty line. Higher value of the Poverty Gap Index shows that the gap between average expenditure of the poor and the poverty line is wider [2]. The Poverty Depth Index in Papua Province in 2019 was the largest value in Indonesia, which is 7.17 while West Papua and East Nusa Tenggara had values of 5.6 and 4.15[3]. This study will analyze observation on the data used by District/City in 2012 to 2019 , so the analysis in this study is panel data regression analysis because it is an analysis that combines cross section based on District/City and time series data.

\section{METHOD}

\subsection{Data Source}

The source of data is secondary data from publication of Badan Pusat Statistika (BPS) of Papua Province. Data was collected using National Socio-Economic Survey.

\subsection{Research Variable}

The variables used in this can be seen in Table 11 . While data structure is shown in Table 2, 3, and 4. The following is the formula to calculate P1 [2].

$$
P_{1}=\frac{1}{n} \sum_{i=1}^{q}\left[\frac{z-y_{i}}{z}\right]
$$

Description:

$z=$ poverty line.

$q=$ Number of people living below the poverty line.

$y_{i}=$ Average monthly expenditure per capita of the population below the poverty line $\left(\mathrm{y}_{\mathrm{i}}<\mathrm{z}\right)$ $n=$ Total population. 
Table 1. Variable

\begin{tabular}{|c|c|c|}
\hline Variable & Description & Scale \\
\hline$X_{1}$ & $\begin{array}{l}\text { Human Development } \\
\text { Indeks }\end{array}$ & Rasio \\
\hline$x_{2}$ & Life Ecpectancy & Ratio \\
\hline$x_{3}$ & $\begin{array}{l}\text { Average Monthly } \\
\text { Expenditure per capita }\end{array}$ & Ratio \\
\hline$X_{4}$ & $\begin{array}{l}\text { Literacy Rate } 15 \text { years old } \\
\text { and over } \\
\text { Percentage of Houshold }\end{array}$ & Ratio \\
\hline$X_{5}$ & $\begin{array}{l}\text { who have purchased poor } \\
\text { rice/prosperous rice }\end{array}$ & Ratio \\
\hline Y & Poverty Depth Index (P1) & Ratio \\
\hline
\end{tabular}

Table 2. Data Structure

\begin{tabular}{|c|c|c|c|c|c|c|}
\hline Time $(t)$ & Individual ( $(\zeta)$ & $Y_{i . t}$ & $X_{1 . i t}$ & $X_{2 \text {.i.t }}$ & $\ldots$ & $X_{5 . i t}$ \\
\hline \multirow{4}{*}{2012} & Dist/City 1 & $Y_{1.1}$ & $X_{1.1 .1}$ & $X_{2.1 .1}$ & $\ldots$ & $X_{5.1 .1}$ \\
\hline & Dist/City 2 & $Y_{2.1}$ & $X_{1.2 .1}$ & $X_{2.2 .1}$ & $\ldots$ & $X_{5.2 .1}$ \\
\hline & $\vdots$ & $\vdots$ & $\vdots$ & $\vdots$ & & $\vdots$ \\
\hline & Dist/City 29 & $Y_{29.1}$ & $X_{1.29 .1}$ & $X_{2.29 .1}$ & $\ldots$ & $X_{5.29 .1}$ \\
\hline$\vdots$ & $\vdots$ & $\vdots$ & $\vdots$ & & $\vdots$ & $\vdots$ \\
\hline \multirow{4}{*}{2018} & Dist/City 1 & $Y_{1.7}$ & $X_{1.1 .7}$ & $X_{2.17}$ & $\ldots$ & $X_{5.1 .7}$ \\
\hline & Dist/City 2 & $Y_{2.7}$ & $X_{1.2 .7}$ & $X_{2.2 .7}$ & $\ldots$ & $X_{5.2 .7}$ \\
\hline & $\vdots$ & $\vdots$ & $\vdots$ & $\vdots$ & & $\vdots$ \\
\hline & Dist/City 29 & $Y_{29.7}$ & $X_{1.29 .7}$ & $X_{2.29 .7}$ & $\ldots$ & $X_{5.29 .7}$ \\
\hline \multirow{4}{*}{2019} & Dist/City 1 & $Y_{1.8}$ & $X_{1.1 .8}$ & $X_{2.1 .8}$ & $\ldots$ & $X_{5.1 .8}$ \\
\hline & Dist/City 2 & $Y_{2.8}$ & $X_{1.2 .8}$ & $X_{2.2 .8}$ & $\ldots$ & $X_{5.2 .8}$ \\
\hline & $\vdots$ & $\vdots$ & $\vdots$ & $\vdots$ & & $\vdots$ \\
\hline & Dist/City 29 & $Y_{29.8}$ & $X_{1.29 .8}$ & $X_{2.29 .8}$ & $\ldots$ & $X_{5.29 .8}$ \\
\hline
\end{tabular}

Table 3. Data Structure with Dummy Time

\begin{tabular}{|c|c|c|c|c|c|c|c|}
\hline Subject (it) & $\mathrm{D}_{1}$ & $D_{2}$ & $\ldots D_{8}$ & $Y_{i . t}$ & $X_{1 . i . t}$ & $\ldots$ & $X_{5 . i t}$ \\
\hline Dist/City 1 (2012) & 1 & 0 & $\ldots 0$ & $Y_{1.1}$ & $X_{1.1 .1}$ & $\ldots$ & $X_{5.1 .1}$ \\
\hline Dist/City 2 (2012) & 1 & 0 & $\ldots 0$ & $Y_{2.1}$ & $X_{1.2 .1}$ & $\ldots$ & $X_{5.2 .1}$ \\
\hline$\vdots$ & $\vdots$ & $\vdots$ & $\vdots$ & $\vdots$ & $\vdots$ & & $\vdots$ \\
\hline Dist/City 29 (2012) & 1 & 0 & $\ldots 0$ & $Y_{29.1}$ & $X_{1.29 .1}$ & $\ldots$ & $X_{5.29 .1}$ \\
\hline Dist/City 1 (2013) & 0 & 1 & ... 0 & $Y_{1.2}$ & $X_{1.1 .2}$ & ... & $x_{5.1 .2}$ \\
\hline Dist/City 2 (2013) & 0 & 1 & ... 0 & $Y_{2.2}$ & $X_{1.2 .2}$ & $\cdots$ & $x_{5.2 .2}$ \\
\hline$\vdots$ & $\vdots$ & $\vdots$ & $\vdots$ & $\vdots$ & $\vdots$ & & $\vdots$ \\
\hline Dist/City 29 (2013) & 0 & 1 & $\ldots 0$ & $Y_{29.2}$ & $X_{1.29 .2}$ & $\ldots$ & $X_{5.29 .2}$ \\
\hline$\vdots$ & $\vdots$ & $\vdots$ & $\vdots \quad \vdots$ & $\vdots$ & & $\vdots$ & $\vdots$ \\
\hline Dist/City 1 (2019) & 0 & 0 & ... 1 & $Y_{1.8}$ & $X_{1.1 .8}$ & $\cdots$ & $X_{5.1 .8}$ \\
\hline Dist/City 2 (2019) & 0 & 0 & ... 1 & $Y_{2.8}$ & $X_{1.2 .8}$ & $\ldots$ & $x_{5.2 .8}$ \\
\hline$\vdots$ & $\vdots$ & $\vdots$ & $\vdots$ & $\vdots$ & $\vdots$ & & $\vdots$ \\
\hline Dist/City 29 (2019) & 0 & 0 & $\ldots 1$ & $Y_{29.8}$ & $X_{1.29 .8}$ & $\ldots$ & $X_{5.29 .8}$ \\
\hline
\end{tabular}

Table 4. Data Structure with Dummy District/City

\begin{tabular}{lcccccccc}
\hline Subjek (it) & $D_{1}$ & $D_{2}$ & $\ldots$ & $D_{29}$ & $Y_{i . t}$ & $X_{1 . i . t}$ & $\ldots$ & $X_{5.1 . t}$ \\
\hline Dist/City1 (2012) & 1 & 0 & $\ldots$ & 0 & $Y_{1.1}$ & $X_{1.1 .1}$ & $\ldots$ & $X_{5.1 .1}$
\end{tabular}

\begin{tabular}{lcccccccc}
\hline Subjek (it) & $D_{1}$ & $D_{2}$ & $\ldots$ & $D_{29}$ & $Y_{i . t}$ & $X_{1.1 . t}$ & $\ldots$ & $X_{5 . i . t}$ \\
\hline Dist/City2 (2012) & 0 & 1 & & 0 & $Y_{2.1}$ & $X_{1.2 .1}$ & $\ldots$ & $X_{5.2 .1}$ \\
$\vdots$ & $\vdots$ & $\vdots$ & $\ldots$ & $\vdots$ & $\vdots$ & $\vdots$ & & $\vdots$ \\
Dist/City29 (2012) & 0 & 0 & $\ldots$ & 1 & $Y_{29.1}$ & $X_{1.29 .1}$ & $\ldots$ & $X_{5.29 .1}$ \\
\hline$\vdots$ & $\vdots$ & $\vdots$ & $\vdots$ & & $\vdots$ & $\vdots$ & $\vdots$ & $\vdots$ \\
\hline Dist/City1 (2018) & 1 & 0 & $\ldots$ & 0 & $Y_{1.7}$ & $X_{1.1 .7}$ & $\ldots$ & $X_{5.1 .7}$ \\
Dist/City2 (2018) & 0 & 1 & $\ldots$ & 0 & $Y_{2.7}$ & $X_{1.2 .7}$ & $\ldots$ & $X_{5.2 .7}$ \\
$\vdots$ & & & & & $\vdots$ & $\vdots$ & & $\vdots$ \\
Dist/City29 (2018) & 0 & 0 & $\ldots$ & 1 & $Y_{29.7}$ & $X_{1.29 .7}$ & $\ldots$ & $X_{5.29 .7}$ \\
\hline Dist/City1 (2019) & 1 & 0 & $\ldots$ & 0 & $Y_{1.8}$ & $X_{1.1 .8}$ & $\ldots$ & $X_{5.1 .8}$ \\
Dist/City2 (2019) & 0 & 1 & $\ldots$ & 0 & $Y_{2.8}$ & $X_{1.2 .8}$ & $\ldots$ & $X_{5.2 .8}$ \\
$\vdots$ & & & & & $\vdots$ & $\vdots$ & & $\vdots$ \\
Dist/City29 (2019) & 0 & 0 & $\ldots$ & 1 & $Y_{29.8}$ & $X_{1.29 .8}$ & $\ldots$ & $X_{5.29 .8}$ \\
\hline
\end{tabular}

\subsection{Panel Data Regression}

Before analysing panel data regression, there is multicollinearity assumption to detect linier relationship between predictor variables. If there is multicollinearity, it can interfere with test results and estimates [4]. One way to detect multicollinearity is to partial correlation values for each variable. If the value is greater than 0.9 then there is a multicollinearity[5]. Panel data is an analysis used in cross section and time series data so that panel data provides more varied Description [4].

\subsection{Panel Data Regression Parameter Estimation}

Panel Data Regression has three models. The following is an approach to estimate the panel data regression.

\subsubsection{Common Effect Model (CEM)}

Common Effect Model analyses cross section and time series data together. The intercept value $\left(\beta_{0}\right)$ in this model is constant in each individual and time [4]. Equation (1) is the Common Effect Model regression equation in matrix form [7].

$$
\mathbf{Y}=\mathbf{X} \boldsymbol{\beta}+\boldsymbol{\varepsilon}
$$

Estimates are made using the Ordinary Least Square (OLS) method as Equation (2).

$$
\hat{\boldsymbol{\beta}}=\left(\mathbf{X}^{\prime} \mathbf{X}\right)^{-1} \mathbf{X}^{\prime} \mathbf{Y}
$$

\subsubsection{Fixed Effect Model (FEM)}

The fixed effect model is divided into three, fixed effect on individuals, fixed effects on time and fixed effects on individuals and time [4]. The following is an explanation of each fixed effect model. 
Individual Fixed Effect Model has a constant slope coefficient value and the intercept coefficient varies for each individual with the assumption that the time effect is ignored. Equation (3) is the individual Fixed Effect Models in matrix form.

$$
\mathbf{Y}=\mathbf{D} \boldsymbol{\alpha}+\mathbf{X} \boldsymbol{\beta}+\boldsymbol{\varepsilon}
$$

Parameter estimation for Fixed Effect Model is performed using Least Square Dummy Variable (LSDV) as follows.

$$
\begin{aligned}
\hat{\boldsymbol{\beta}}_{L S D V} & =\left[\sum_{i=1}^{n}\left(\mathbf{M}^{0} \mathbf{X}_{i}\right)^{\prime} \mathbf{M}^{0} \mathbf{X}_{i}\right]^{-1}\left[\sum_{i=1}^{n}\left(\mathbf{M}^{0} \mathbf{X}_{i}\right)^{\prime} \mathbf{M}^{0} \mathbf{Y}_{i}\right] \\
& =\left[\sum_{i=1}^{n} \ddot{\mathbf{X}}_{i}^{\prime} \ddot{\mathbf{X}}_{i}\right]^{-1}\left[\sum_{i=1}^{n} \ddot{\mathbf{X}}_{i} \ddot{\mathbf{Y}}_{i}\right] \\
& =(\ddot{\mathbf{X}} \ddot{\mathbf{X}})^{-1}(\ddot{\mathbf{X}} \ddot{\mathbf{Y}})
\end{aligned}
$$

On the other hand, the Fixed Effect Model on time has a constant slope coefficient value and the intercept coefficient varies over time assuming that individual effects are ignored [4]. Equation (4) is Fixed Effect Time model in matrix form.

$$
\mathbf{Y}=\mathbf{D} \boldsymbol{\lambda}+\mathbf{X} \boldsymbol{\beta}+\boldsymbol{\varepsilon}
$$

Fixed Effect Individual and time effects model has a constant slope coefficient value, and the intercept coefficient varies between individuals and time [4]. Equation (5) is Fixed Effect Model individual and time in matrix form. [8].

$$
\mathbf{Y}=\mathbf{D} \boldsymbol{\alpha}+\mathbf{D} \boldsymbol{\lambda}+\mathbf{X} \boldsymbol{\beta}+\boldsymbol{\varepsilon}
$$

The estimation is based on the Least Square Dummy Variable method as in the previous discussion. The model is assumed that there is no time-invariant on variable $\mathrm{X}$. The group mean matrix is obtained as follows.

$$
\begin{aligned}
\mathbf{D}\left(\mathbf{D}^{\prime} \mathbf{D}\right)^{-1} \mathbf{D}^{\prime} \mathbf{X} & =\mathbf{P}_{\mathbf{D}} \mathbf{X} \\
& =\left(\mathbf{1}-\mathbf{M}_{\mathbf{D}}\right) \mathbf{X}
\end{aligned}
$$

Then the least squares regression of $\mathbf{Y}$ on $\mathbf{X}$ and $\mathbf{P}_{\mathbf{D}} \mathbf{X}$, namely on $\mathbf{X}$ and the group mean, $\overline{\mathbf{X}}$. By using the partitioned regression formula, the estimator is as follows.

$$
\begin{aligned}
\mathbf{b}_{\text {Mundlak }} & =\left(\mathbf{X}^{\prime} \mathbf{M}_{\mathbf{P X}} \mathbf{X}\right)^{-1} \mathbf{X}^{\prime} \mathbf{M}_{\mathbf{P X}} \mathbf{Y} \\
& =\left\{\mathbf{X}^{\prime}\left[\mathbf{I}-\overline{\mathbf{X}}(\overline{\mathbf{X}} \overline{\mathbf{X}})^{-1} \overline{\mathbf{X}}^{\prime}\right] \mathbf{X}\right\}^{-1} \times\left\{\mathbf{X}^{\prime}\left[\mathbf{I}-\overline{\mathbf{X}}(\overline{\mathbf{X}} \overline{\mathbf{X}})^{-1} \overline{\mathbf{X}}^{\prime}\right] \mathbf{Y}\right\}^{-1}
\end{aligned}
$$

The $\mathbf{P}_{\mathbf{D}}$ matrix at $\overline{\mathbf{X}}=\mathbf{P}_{\mathbf{D}} \mathbf{X}$ and is idempotent. The first matrix in brackets will be expanded to become the following equation.

$$
\begin{aligned}
\left\{\mathbf{X}^{\prime}\left[\mathbf{I}-\left(\mathbf{P}_{\mathrm{D}} \mathbf{X}\right)\left[\left(\mathbf{P}_{\mathrm{D}} \mathbf{X}\right)^{\prime}\left(\mathbf{P}_{\mathrm{D}} \mathbf{X}\right)\right]^{-1}\left(\mathbf{P}_{\mathrm{D}} \mathbf{X}\right)^{\prime}\right]\right] & \mathbf{X}\} \\
& =\mathbf{X} \mathbf{X}-\mathbf{X} \mathbf{P}_{\mathrm{D}} \mathbf{X}\left[\mathbf{X} \mathbf{P}_{\mathrm{D}}^{\prime} \mathbf{P}_{\mathrm{D}} \mathbf{X}\right]^{-1} \mathbf{X} \mathbf{P}_{\mathrm{D}}^{\prime} \mathbf{X} \\
& =\mathbf{X} \mathbf{X}-\mathbf{X} \mathbf{P}_{\mathrm{D}} \mathbf{X} \\
& =\mathbf{X}\left[\mathbf{I}-\mathbf{P}_{\mathrm{D}}\right] \mathbf{X} \\
& =\mathbf{X} \mathbf{M}_{\mathrm{D}} \mathbf{X}
\end{aligned}
$$

\subsubsection{Random Effect Model (REM)}

Random Effect Models can represent period-specific differences that are not captured by the specified regressor. The equation (6) is Random Effect Model.

$Y_{i t}=\beta_{0 i}+\beta_{1} X_{1 i t}+\beta_{2} X_{2 i t}+\ldots+\beta_{k} X_{k i t}+\eta_{i t}$

Where:

$\eta_{i t}=\varepsilon_{i t}+u_{i}$

Description:

$\eta_{i t}=$ model component error

$\varepsilon_{i t}=$ regression error of individual $i$ and time $t$

$u_{i}=$ regression error of random effect on individual $i$

This estimation is using Generalized Least Square (GLS) method because it can eliminate heteroscedasticity [8]. Generalized Least Square estimation is as follows.

$\hat{\boldsymbol{\beta}}=\left(\mathbf{X}^{\prime} \mathbf{\Omega}^{-1} \mathbf{X}\right)^{-1} \mathbf{X}^{\mathbf{\prime}} \mathbf{\Omega}^{-1} \mathbf{Y}$

\subsection{Selection of the Best Model}

\subsubsection{Individual Chow Test}

Chow test was conducted to select a model between Common Effect Model and Fixed Effect Model [8].

$\mathrm{H}_{0}: \alpha_{1}^{2}=\alpha_{2}{ }^{2}=\ldots=\alpha_{\mathrm{n}}{ }^{2}=0$ (Common Effect Model is appropriate)

$\mathrm{H}_{1}$ : At least one $\alpha_{\mathrm{i}}^{2} \neq 0$ (Fixed Effect Model is appropriate)

Test statistics:

$$
F_{\text {hitung }}=\frac{\left(R_{L S D V}^{2}-R_{\text {pooled }}^{2}\right) /(n-1)}{\left(1-R_{L S D V}^{2}\right) /(n T-n-k)}
$$

The rejection area for the chow test with a significant

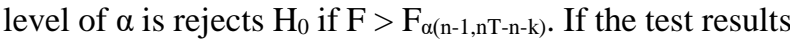
reject $\mathrm{H}_{0}$, then the test will proceed to the Hausman test. If the test results fail to reject $\mathrm{H}_{0}$, then the test will continue to the Lagrange Multiplier test.

\subsubsection{Hausman test}

Hausman test was conducted to select model between Fixed Effect Model and Random Effect Model [8].

$\mathrm{H}_{0}: \operatorname{corr}\left(\mathrm{X}_{\mathrm{it}}, \quad \varepsilon_{\mathrm{it}}\right)=0$ (Random Effect Model is appropriate)

$\mathrm{H}_{1}$ : $\operatorname{corr}\left(\mathrm{X}_{\mathrm{it}}, \varepsilon_{\mathrm{it}}\right) \neq 0$ (Fixed Effect Model is appropriate)

Test statistics:

$W=\left(\mathbf{b}_{F E M}-\hat{\boldsymbol{\beta}}_{R E M}\right)^{\prime}\left(\operatorname{var}\left[\mathbf{b}_{F E M}\right]-\operatorname{var}\left[\hat{\boldsymbol{\beta}}_{R E M}\right]\right)^{-1}\left(\mathbf{b}_{F E M}-\hat{\boldsymbol{\beta}}_{R E M}\right)$

The rejection area with a significant level of $\alpha$ is rejected $\mathrm{H}_{0}$ if $\mathrm{W}>\chi_{\alpha ; \mathrm{k}-1}^{2}$. If the test results reject $\mathrm{H}_{0}$, then the best model on the data is the Fixed Effect Model. 
However, if the test results fail to reject $\mathrm{H}_{0}$, it will be continued with testing using the Lagrange Multiplier test.

\subsubsection{Lagrange Multiplier Test}

The Lagrange Multiplier test was conducted to select model between Common Effect Model and Random Effect Model [8].

$\mathrm{H}_{0}: \sigma_{\mathrm{u}}^{2}=0$ (Common Effect Model is appropriate)

$\mathrm{H}_{1}: \sigma_{\mathrm{u}}^{2}>0$ (Random Effect Model is appropriate)

Test statistics:

$L M=\frac{N T}{2(T-1)}\left[\frac{\sum_{i=1}^{N}\left[\sum_{t=1}^{T} e_{i t}\right]^{2}}{\sum_{i=1}^{N} \sum_{t=1}^{T} e_{i t}^{2}}-1\right]^{2}$

The rejection area with a significant level of $\alpha$ is rejected $\mathrm{H}_{0}$ if $\mathrm{LM}>\chi_{\alpha ; 1}^{2}$. If the test results reject $\mathrm{H}_{0}$, then the best model on the data is the Random Effect Model. However, if the test results fail to reject $\mathrm{H}_{0}$, then the best model is the Common Effect Model.

\subsection{Assumption Test}

\subsubsection{Testing Assumptions of Residual Covariance Variance Structure}

Testing the structural assumptions on the Fixed Effect Model with individual effects is carried out using the Lagrange Multiplier Test [8].

$\mathrm{H}_{0}: \sigma^{2}{ }_{\mathrm{i}}=0$ (Fixed Effect Model is homoscedasticity)

$\mathrm{H}_{1}: \sigma^{2}{ }_{\mathrm{i}} \neq 0$ (Fixed Effect Model is heteroscedasticity)

$$
L M=\frac{T}{2} \sum_{i=1}^{N}\left[\frac{\sigma_{i}^{2}}{\sigma^{2}}-1\right]^{2}
$$

The rejection area for Lagrange Multiplier test with a significant level of $\alpha$ is $\mathrm{H}_{0}$ rejection if $\mathrm{LM}>\chi_{\alpha ; \mathrm{N}-1}^{2}$. If the model has heteroscedasticity, then the analysis is Fixed Effect Model with cross section weighted and the estimation is using Generelized Least Squares (GLS).

\subsubsection{Testing Assumptions of Correlation Between Cross Sections}

Testing the assumption of correlation between cross sections is analyzed when it is concluded the structure of the variance of the residual covariance is heteroscedastic.

$\mathrm{H}_{0}$ : corr $\left(\varepsilon_{\mathrm{it}}, \varepsilon_{\mathrm{jt}}\right)=0$ (no correlation between cross sections)

$\mathrm{H}_{1}$ : corr $\left(\varepsilon_{\mathrm{it}}, \varepsilon_{\mathrm{jt}}\right) \neq 0$ (there is a correlation between cross sections)
$\lambda_{L M}=T \sum_{n=2}^{N} \sum_{m=1}^{n-1} r_{n m}^{2}$

$\mathrm{r}_{\mathrm{mn}}^{2}$ is the residual correlation coefficient between the $i$-th and $j$-th equations. The rejection area for testing the correlation between cross sections with a significant level

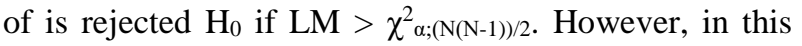
study it will be assumed that there is no correlation to the unit cross section.

\subsubsection{Normal Distribution Assumption Test}

Assumption of normal distribution residuals is analyzed to detect whether the residuals of model follow normal distribution with Kolmogorov Smirnov test. [10].

$\mathrm{H}_{0}: \mathrm{F}(\mathrm{e})-\mathrm{F}_{0}(\mathrm{e})=0$ (residual model is normally distributed)

$\mathrm{H}_{1}$ : $\mathrm{F}(\mathrm{e})-\mathrm{F}_{0}(\mathrm{e}) 0$ (residual model is not normally distributed)

Test statistics:

$$
K S=S U P\left|S(e)-F_{0}(e)\right|
$$

Description:

$\mathrm{KS}_{\alpha}=$ the critical area of the kolmogorov-smirnov test one sample obtained from the table kolmogorov-smirnov one sample

$\mathrm{F}_{0}(\mathrm{e})=$ normal cumulative distribution of $\mathrm{Z}$ values in the sample

$\mathrm{F}(\mathrm{e})=$ sample cumulative frequency distribution value

$\mathrm{S}(\mathrm{e})=$ empirical cumulative frequency distribution of observations in sorted samples

SUP $=$ maximum value

The rejection area for testing the normal distribution assumption with a significant level used of is rejected $\mathrm{H}_{0}$ if $\mathrm{KS}>\mathrm{KS}_{\alpha, \mathrm{n}}$.

\section{RESULT AND DISCUSION}

\subsection{Characteristics of Poverty Depth Index in Papua Province and the Factors That Are Suspected to Affect It}

\subsubsection{Characteristics of Poverty Depth Index \\ Data in Papua Province from 2012 to 2019}

The following are the characteristics of the Poverty Depth Index data in Papua Province from 2012 to 2019. 


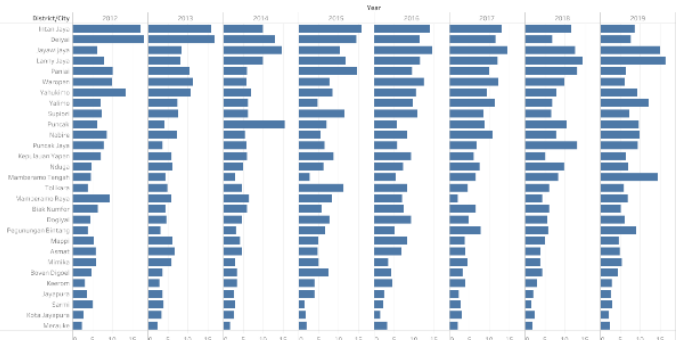

Figure 1 Characteristics of Poverty Depth Index in Papua Province from 2012 to 2019.

Figure 1 shows that the area that has the largest Poverty Depth Index value in 2019 is Lanny Jaya District and the area that has the lowest is Merauke District. Thanks to various pro-poor and equity policies, the Papuan government has succeeded in reducing the P1 gap to 1.87 in 2017 and 0.77 in 2018 . However, the lack of basic service facilities and infrastructure is the main cause of poverty, mostly in mountainous areas.

\subsubsection{Characteristics of Human Development Index Data in Papua Province from 2012 to 2019}

The following are the characteristics of the Human Development Index data in Papua Province from 2012 to 2019.

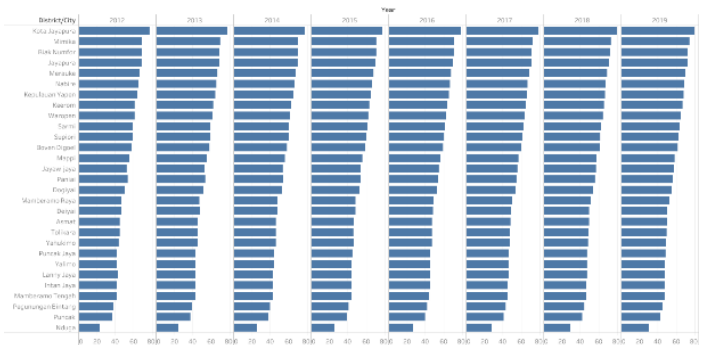

Figure 2 Characteristics of Human Development Index in Papua Province from 2012 to 2019.

Figure 2 shows the largest Human Development Index in 2012 to 2019 is in Jayapura City, while the lowest Human Development Index value is in Nduga District. The acceleration of human development in Papua is relatively fast with an increase is $5.29 \%$ from 2012 to 2019 and the average increase per year is $0.755 \%$. The highest increase was in 2017 which was $1.04 \%$. However, the human development gap in Papua Province is still very high. This can be seen in 2019 the difference between the highest and lowest Human Development Index, Jayapura City and Nduga District is $160.68 \%$.

\subsubsection{Characteristics of Life Expectancy Data in Papua Province from 2012 to 2019}

The following are the characteristics of life expectancy data in Papua Province from 2012 to 2019.

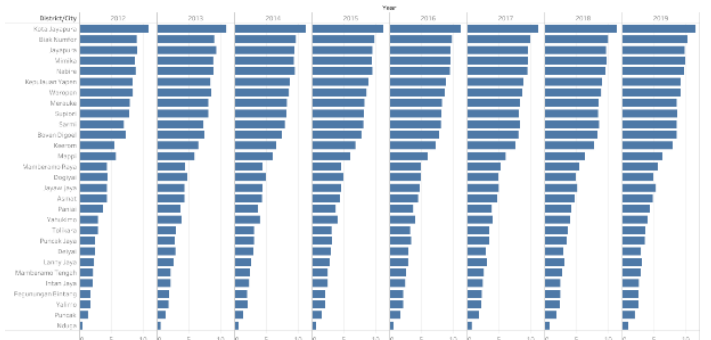

Figure 3 Characteristics of Life Expectancy in Papua Province from 2012 to 2019.

Figure 3 shows the areas that have the largest life expectancy in 2012 to 2019 are Merauke District and Jayapura City, while the areas with the lowest life expectancy are Asmat District and Nduga District. The increase in life expectancy in Papua reached $1.05 \%$ from 2012 to 2019 with an average annual increase of $0.15 \%$ and the highest increase in this value was in 2019 at $0.29 \%$

\subsubsection{Data Characteristics of Average Monthly Expenditure per Capita in Papua Province from 2012 to 2019}

The following are the characteristics of the Average Monthly Expenditure per Capita data in Papua Province from 2012 to 2019.

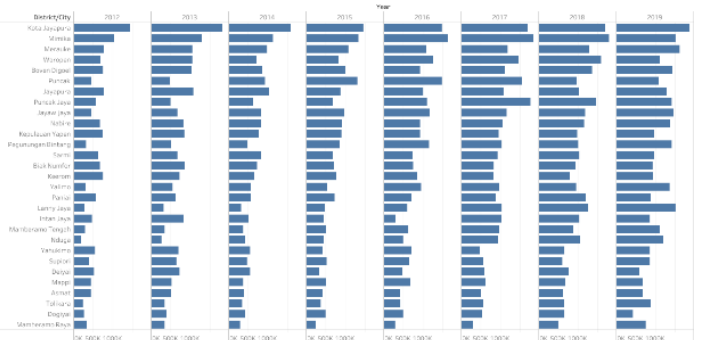

Figure 4 Characteristics of Average Monthly Expenditure per Capita in Papua Province from 2012 to 2019.

Figure 4 shows that the value of the Average Monthly Expenditure per Capita in Districts/Cities in Papua Province tends to increase every year. This happens because people's purchasing power to meet their daily needs has increased by Rp. 823,915 since 2012 so that in 2019 the average per capita expenditure was Rp. $1,459,494$ with an average increase of Rp. 117,702.14 per year. However, there are areas that have declining values, one of which is Dogiyai District in 2019 the Average Monthly Expenditure per Capita value in that area decreased so that the value in the Greater Membrano area was greater. The area that has the largest Average Monthly Expenditure per Capita value in 2019 is Jayapura City and the area that has the lowest Average Monthly Expenditure per Capita value is Dogiyai District. 


\subsubsection{Data Characteristics of Literacy Rates Age 15 and Over in Papua Province from 2012 to 2019}

The following are the characteristics of the literacy rate data for ages 15 years and over in Papua Province from 2012 to 2019.

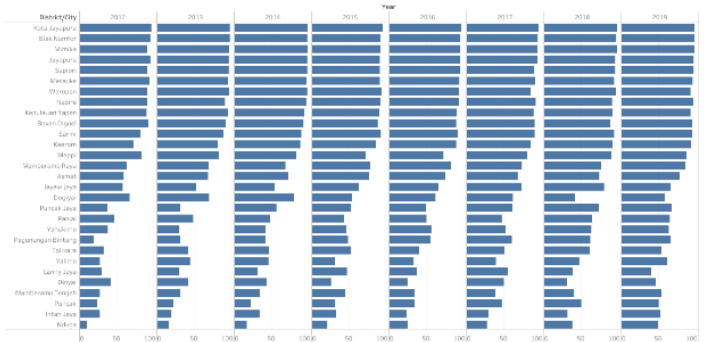

Figure 5 Characteristics of Literacy Rates Age 15 and Over in Papua Province from 2012 to 2019.

Figure 5 shows that the literacy rate of 15 years and over in districts/cities in Papua Province tends to increase every year. This happens because of the success in running the literacy program. The increase in the literacy rate for residents 15 years of age and over in Papua reached $12.31 \%$ from 2012 to 2019 with an average annual increase of $1.76 \%$. However, Dogiyai District in 2018 had a literacy rate of 15 years and over lower than the previous year. The area that has the largest literacy rate aged 15 years and over in 2019 is Jayapura City, while the area that has the lowest literacy rate is Lanny Jaya District.

\subsubsection{Data Characteristics of Percentage of Households Who Have Purchased Poor/Prosperous Rice in Papua Province from 2012 to 2019}

The following are characteristic of the Percentage of Households Who Have Purchased Poor/Prosperous Rice in Papua Province from 2012 to 2019.

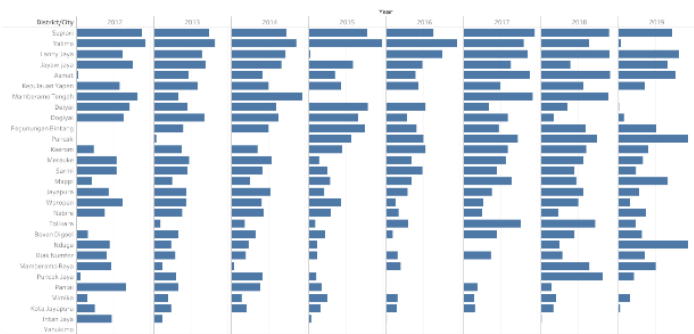

Figure 6 Characteristics of Percentage of Households Who Have Purchased Poor/Prosperous Rice in Papua Province from 2012 to 2019.
Figure 6 shows that Lanny Jaya District has a relatively high Percentage of Households that Have Purchased Rice for Poor/Rice Prosperity in 2012 and decreased drastically in 2015 and rose again the following year. The area that has the largest Percentage value of Households that Have Purchased Poor Rice/Rice Welfare in 2019 is Nduga District and Puncak District, while the area that has the lowest Percentage value of Households that Have Purchased Poor/Prosperous Rice is Yahukimo District.

\subsection{Panel Data Regression Analysis Factors Suspected Influencing Poverty Depth Index Data in Papua Province}

\subsubsection{Multicollinearity Analysis of Factors Suspected of Influencing Poverty Depth Index Data in Papua Province}

Multicollinearity analysis was performed using the correlation values shown in Table 5.

Table 5. Multicollinearity Analysis of Factors Suspected of Affecting Poverty Depth Index in Papua Province

\begin{tabular}{llllll}
\hline Variable & $\mathbf{X}_{\mathbf{1}}$ & $\mathbf{X}_{\mathbf{2}}$ & $\mathbf{X}_{\mathbf{3}}$ & $\mathbf{X}_{\mathbf{4}}$ & $\mathbf{X}_{\mathbf{5}}$ \\
\hline $\mathrm{X}_{1}$ & 1.000 & 0.630 & 0.508 & 0.880 & -0.051 \\
$\mathrm{X}_{2}$ & 0.630 & 1.000 & 0.419 & 0.360 & -0.071 \\
$\mathrm{X}_{3}$ & 0.508 & 0.419 & 1.000 & 0.428 & -0.063 \\
$\mathrm{X}_{4}$ & 0.880 & 0.360 & 0.428 & 1.000 & 0.021 \\
$\mathrm{X}_{5}$ & -0.051 & -0.071 & -0.063 & 0.021 & 1.000 \\
\hline
\end{tabular}

Table 5 shows that there is no multicollinearity in the variables thought to affect the Poverty Depth Index in Papua Province. This can be seen from all the variables that have a correlation value of less than 0.9. So, the five variables have met multicollinearity assumption and panel data regression analysis can be performed.

\subsubsection{Panel Data Regression Analysis with Common Effect Model (CEM) Poverty Depth Index in Papua Province}

The following is the result of parameter estimation in this model using the OLS method.

$$
\begin{aligned}
P 1= & 8.311-0.0176 X_{1}+0.0383 X_{2}+1.66^{-6} X_{3}-0.066 X_{4} \\
& +0.0096 X_{5}
\end{aligned}
$$

The model that is formed has an R-Squared value of 0.213 which means that the predictor variable can explain the model by $21.3 \%$. The results of the significance test with a significant level of 0.05 obtained variables that have a significant effect on the Poverty Depth Index in Papua Province are variables $\mathrm{X}_{3}$ and $\mathrm{X}_{4}$. 


\subsubsection{Panel Data Regression Analysis with Fixed Effect Model (FEM) Poverty Depth Index in Papua Province Individual Effects}

The following is the result of panel data regression analysis using the Fixed Effect Model with individual effects.

$$
\begin{aligned}
P 1= & 10.979-0.572 X_{1}+0.334 X_{2}+5.38 \times 10^{-6} X_{3}+0.021 X_{4} \\
& -0.0015 X_{5}
\end{aligned}
$$

The model that is formed has an R-Squared value of 0.728 which means that the predictor variable can explain the model by $72.8 \%$. The results of the significance test with a significant level of 0.05 obtained variables that have a significant effect on the Poverty Depth Index in Papua Province are variables $\mathrm{X}_{1}$ and $\mathrm{X}_{3}$.

\subsubsection{Panel Data Regression Analysis with Fixed Effect Model (FEM) Poverty Depth Index in Papua Province Time Effect}

The following is the result of panel data regression analysis using Fixed Effect Model (FEM) with time effect.

$$
\begin{aligned}
P 1= & 8.16-0.015 X_{1}+0.042 X_{2}+1.34 \times 10^{-6} X_{3}-0.066 X_{4} \\
& +0.011 X_{5}
\end{aligned}
$$

The model that is formed has an R-Squared value of 0.228 , which means that the predictor variable can explain the model by $22.8 \%$. The results of the significance test with a significant level of 0.05 obtained a variable that has a significant effect on the Poverty Depth Index in Papua Province is variable $\mathrm{X}_{4}$.

\subsubsection{Panel Data Regression Analysis with Fixed Effect Model (FEM) Poverty Depth Index in Papua Province Individual and Time Effects}

The following is the result of panel data regression analysis using the Fixed Effect Model with individual and time effects.

$$
\begin{aligned}
P 1 & =28.945-0.229 X_{1}+0.284 X_{2}+5.41 \times 10^{-6} X_{3}+0.01 X_{4} \\
& -0.0016 X_{5}
\end{aligned}
$$

The model that is formed has an R-Squared value of 0.752 which means the predictor variable can explain the model by $75.2 \%$. The results of the significance test with a significant level of 0.05 obtained a variable that has a significant effect on the Poverty Depth Index in Papua Province is variable $\mathrm{X}_{3}$.

\subsubsection{Panel Data Regression Analysis with Random Effect Model (REM) Poverty Depth Index in Papua Province}

The following is the result of panel data regression analysis using the Random Effect Model (REM).

$$
\begin{aligned}
P 1= & 6.508-0.219 X_{1}+0.144 X_{2}+3.82 \times 10^{-6} X_{3} \\
& +0.001 X_{4}-0.0003 X_{5}
\end{aligned}
$$

The model that is formed has an R-Squared value of 0.157 which means the predictor variable can explain the model by $15.7 \%$. The results of the significance test with a significant level of 0.05 obtained variables that have a significant effect on the Poverty Depth Index in Papua Province are variables $\mathrm{X}_{1}$ and $\mathrm{X}_{3}$.

\subsection{Analysis of the Best Model Selection}

Analysis of model selection using the Chow test was carried out by comparing the Common Effect Model and the Fixed Effect Model of individual effects. The results of the model selection with the Chow test have F value of 13.376 which is greater than the table value of 2.253. So, it can be decided to reject $\mathrm{H}_{0}$ or Fixed Effect Model individual effects is more suitable.

Hausman test obtained a W value of 15.752 which is greater than the table value of 9.488 . So, it can be decided to reject $\mathrm{H}_{0}$ or Fixed Effect Model individual effects is more suitable.

The Lagrange Multiplier test produces a test statistic value of 129.2771 which is greater than the table value of 41.337, indicating that the Fixed Effect Model of individual effects has a heteroscedastic structure and will be analysed using cross section weights. The results of these calculations obtained significant variables are $\mathrm{X}_{1}$ and $\mathrm{X}_{3}$.

The following are the results Fixed Effect Model of individual effects with cross section weights on significant variables.

$$
P 1=24.413-0.389 X_{1}+4.74 \times 10^{-6} X_{3}
$$

The model above shows that every one percent increase in the Human Development Index in Papua Province will reduce the Poverty Depth Index value in Papua Province by 0.389 percent with the condition that the variable Average Expenditure per capita in one month is constant. Meanwhile, every increase in Average Expenditure per capita in one month of Rp. 1,000,000 will increase the Poverty Depth Index in Papua Province by 4.74 percent with the condition that the Human Development Index variable is constant. Table 6 shows the intercept variables for each individual. 
Table 6. Individual Effects

\begin{tabular}{cccccc}
\hline CROSSID & Effect & CROSSID & Effect & CROSSID & Effect \\
\hline 1 & -1.0262 & 11 & 0.2243 & 21 & -10.2804 \\
2 & 4.3583 & 12 & -3.1388 & 22 & 1.2293 \\
3 & 1.0777 & 13 & 0.5217 & 23 & -3.9681 \\
4 & 4.9570 & 14 & -6.7179 & 24 & -2.3447 \\
5 & 3.7936 & 15 & -2.1308 & 25 & -5.3738 \\
6 & 5.3202 & 16 & -1.5188 & 26 & -0.0087 \\
7 & 3.2623 & 17 & 0.2068 & 27 & 3.0237 \\
8 & -4.2007 & 18 & 4.4340 & 28 & 4.2805 \\
9 & 1.1476 & 19 & 4.5754 & 29 & 0.9877 \\
10 & -1.8713 & 20 & -0.8196 & & \\
\hline
\end{tabular}

The model has an R-Squared value of 0.825 which means predictor variable can explain model by $82.5 \%$. The results of the significance test with a significant level of 0.05 found that the variables $X_{1}$ and $X_{3}$ had a significant effect on the Poverty Depth Index in Papua Province.

The assumption of a normal distribution is using the Kolmogorov-Smirnov. The results of the analysis has a test statistic Kolmogorov Smirnov value of 0.063 which is less than the table value of 0.089 . So the decision is fail to reject $\mathrm{H}_{0}$, which means that the residuals in the Fixed Effect Model (FEM) individual effects with cross section weighted variables $\mathrm{X}_{1}$ and $\mathrm{X}_{3}$ on the data of Poverty Depth Index in Papua Province from 2012 to 2019 is normally distributed.

\section{CONCLUSION AND SUGESTION}

\subsection{Conclusion}

1. The regions that have the largest Poverty Depth Index in Papua Province in 2019 is Lanny Jaya District. The population condition in Nduga District is not good because it has the lowest Human Development Index, Life Expectancy, Literacy Rate aged 15 and over in 2019. Nduga District also has the largest percentage of households that have purchased Poor Rice/Prosperous Rice in 2019. Meanwhile, the lowest average expenditure per capita in one month is Dogiyai District.

2. The best model in this analysis is the Fixed Effect Model (FEM) with individual effects using cross section weights with significant variables are $\mathrm{X}_{1}$ and $\mathrm{X}_{3}$ and the $\mathrm{R}$-Squared value is $82.5 \%$.

\subsection{Suggestion}

The suggestion that can be given based on the conclusion of the panel regression analysis is Papua Government should be focus on the variables of the Human Development Index and average expenditure per capita in one month if they want to reduce the Poverty Depth Index in Papua because these two variables affect the Poverty Depth Index in Papua Province. In addition, the Papuan provincial government can pay attention to development in hinterland areas or suburbs, because there are development gaps in these areas. One of them is Nduga District, which has poor population conditions.

\section{AUTHORS' CONTRIBUTIONS}

Study conception and design, analysis, and interpretation of description variables: Erma Oktania Permatasari; analysis and interpretation of panel regression and draft manuscript preparation: Rufina Indriani. All authors reviewed the results and approved the final version of the manuscript.

\section{ACKNOWLEDGMENTS}

The authors acknowledge Badan Pusat Statistika of Papua Province for willing to provide data for this journal.

\section{REFERENCES}

[1] Badan Pusat Statistik Provinsi Papua, INDIKATOR KESEJAHTERAAN RAKYAT PROVINSI PAPUA 2018/2019, Jayapura: Badan Pusat Statistik Provinsi Papua, 2019.

[2] Badan Pusat Statistik Provinsi Papua, Provinsi Papua Dalam Angka 2020, Jayapura: Badan Pusat Statistik Provinsi Papua, 2020.

[3] Badan Pusat Statistik, DATA DAN INFORMASI KEMISKINAN KABUPATEN/KOTA TAHUN 2019, Badan Pusat Statistik, 2019.

[4] D. N. Gujarati and D. C. Porter, Basic Econometrics Fifth Edition, The McGraw-Hill, 2009.

[5] D. Asteriou and S. G. Hall, Applied Econometrics: A Modern Approach Revised Edition, New York: Palgrave Macmillan, 2007.

[6] B. H. Baltagi, Econometric Analysis of Panel Data, West Sussex: John Wiley \& Sons Inc, 2005.

[7] D. C. Montgomery, E. A. Peck and G. G. Vining, INTRODUCTION TO LINEAR REGRESSION ANALYSIS, New Jersey: John Wiley \& Sons, Inc, 2012.

[8] W. H. Greene, ECONOMETRIC ANALYSIS, London: Pearson Education, 2012.

[9] N. Drapper and H. Smith, Analisis Regresi Terapan Edisi Kedua, Jakarta: PT Gramedia Pustaka Utama, 1992.

[10] W. W. Daniel, Statistik Nonparametrik, Jakarta: Gramedia Pustaka Utama, 1989. 